\title{
Cuidando el proceso lector desde las bibliotecas
}

Taking care of the reading process from libraries

\author{
Mercè Escardó I Bas \\ Biblioteca Infantil y Juvenil Can Butjosa, La salut, 52 E-08150 Parets del Vallès. España, bibut@parets.cat, http://bibut.parets.cat
}

\section{Resumen}

La biblioteca es un espacio de reflexión, de formación, de convivencia, educador gracias a la lectura. Una lectura que, cuidada esmeradamente desde antes de nacer, llega a convertirse en una herramienta indispensable de crecimiento personal. Es preciso conocer el proceso lector y seguir paso a paso este desarrollo respetando la singularidad y libertad de cada lector, partiendo de una "filosofía propia" que cada biblioteca debe elaborar y que todo el equipo debe hacerse suya para trabajar con coherencia, no haciendo sino siendo, para llegar a ser un espacio de intervención socio-educativo, una biblioteca educadora; estableciendo el tandem biblioteca-escuela-familia y pedaleando juntos hacia la lectura para hacer posible y acompañar el paso de la oralidad a la literatura.
\end{abstract}

Palabras clave: Bibliotecas infantiles y juveniles. Bibliotecas públicas. Lectura. Educación. Animación a la lectura. Proceso lector. Desarrollo.

\section{Desde dónde}

Can Butjosa es una biblioteca especializada del, y para el público infantil y juvenil.

Es una biblioteca rara, poco común, no existe en Catalunya ninguna otra biblioteca con esta especialización; única por su manera de interpretar las misiones que como biblioteca pública ha de cumplir y por tener una filosofía propia que da cuerpo a todo lo que en ella se realiza, especial como lo somos cada uno de nosotros, diferentes y únicos, cada uno a nuestra manera; maravillosa, un lugar dónde se trabaja con la fantasía como aliada en esta tenue línea que une la realidad con la imaginación; inquieta y exploradora, no se conforma con los caminos sabidos, lee, escucha, participa, busca, conoce... y sobretodo cree que la lectura es una herramienta de crecimiento personal insustituible.

Una biblioteca que hemos convertido, gracias a la lectura, en un espacio de intervención socioeducativa, es decir, en un espacio de convivencia que posibilita el anclaje físico en el espacio y el tiempo real a la vez que proporciona, gracias a la lectura, el anclaje interior en un espa-

\begin{abstract}
Libraries are spaces for reflecting, learning, living together, educating... thanks to reading. Reading is the centre of the library and must be promoted with care, even before birth, because it is an indispensable tool for personal development. The process of reading must be studied and followed step by step respecting the idiosincrasy and freedom of each reader. Each library should build its "own philosophy", which all the team members must interiorize and do their own. Thus, the staff will work in a coherent way -being and not simply doing - to create a space for socioeducational intervention, an educative library; creating a library-school-family tandem, so they cycle toguether towards reading, actualizing and supporting the transit from orality towards literature.
\end{abstract}

Keywords: Children and juvenile libraries. Public libraries. Reading. Education. Reading promotion. Reading process. Development.

cio/tiempo que cuida, que agombola (1), en un espacio educador.

Tiene como misión principal el acercamiento a la lectura y el fomento lector de los niños y jóvenes. Todo lo que en ella se vive y se hace está dirigido a lograr este objetivo. Cada niño algunos, desde la barriga de la madre, y otros, que ya han crecido y son jóvenes- recibe en el día a día un tratamiento cuidadoso e individual que le permite dibujar su itinerario como lector.

Además de esta atención individualizada, hemos construido un tejido de animación, con actividades y refuerzos destinados a cuidar del proceso lector.

Tener un tejido de animación significa hacer bien nuestro trabajo de acompañar sostener y arropar a nuestros lectores en todo su proceso lector, elaborando actividad a actividad, refuerzo a refuerzo, ese tejido a la vez suave y fuerte que, precisamente porque está hecho en casa con las herramientas que nos son propias, tiene denominación de origen.

En nuestra biblioteca coexisten, día a día, lector a lector, más de 100 acciones: actividades, en las que los usuarios participan libremente; y 
refuerzos que, aunque no son conscientemente recibidos por nuestros lectores, van impregnándolos de los objetivos educativos que les son propios y los consolidan, amplificando los de las acciones que emprendemos.

La biblioteca está ubicada en Parets del Vallès, municipio de 18.608 habitantes en la comarca del Vallès Oriental a $26 \mathrm{~km}$. de Barcelona. Nació el 10 de abril de 1983 fruto de un convenio entre la Generalitat de Catalunya y el Ayuntamiento de Parets del Vallès (2).

\section{El por qué: la lectura}

Es importante para los profesionales que hacemos de puente entre los niños y los libros que hagamos un alto en el camino para redescubrir que es leer. Hacernos algunas preguntas necesarias para después avanzar en el sendero de la lectura:

- ¿Cómo es que la mayoría de las personas no saben leer más allá de descifrar hileras de hormigas?

- ¿Por qué no se lee de la misma manera que se camina, que se respira...?

- ¿Cómo se hace el aprendizaje? ¿A su tiempo?

- ¿Fallan los libros? ¿Su contenido? ¿Los elegimos bien?

- ¿Se tiene tiempo para leer? ¿Por qué no se prioriza a otras actividades?

- ¿Por qué desde las bibliotecas queremos hacer leer a los demás? ¿Con qué intención?

Intentar responderlas nos llevó a redactar una declaración de intenciones; más aún: a definir una "filosofía propia".

Nos dimos cuenta que no podríamos hacer nada sin ella; y que, antes de empezar cualquier proyecto, era más que necesario tenerla escrita para que, después, estuviera presente en todo lo que lleváramos a cabo, y que todo el equipo la sintiera como propia y la cumpliera.

Esa "filosofía" propia tenía que incluir los hitos y objetivos y una profunda declaración de intenciones, sentida como aquella pequeña verdad que, una vez escrita, nos ayudará a mantenernos firmes y a tomar decisiones con coherencia.

Una filosofía que recogiera los objetivos que queríamos alcanzar y nos llevara a plantearnos seriamente el como implantarlos.
$\mathrm{Y}$ aparecieron nuestros tres objetivos, que, como columnas salomónicas, aguantarían nuestro futuro hacer.

\section{Objetivos globales}

1. Ayudar a los niños y jóvenes a convertirse en unos buenos usuarios de biblioteca que se muevan con facilidad, que no tengan bibliotecafobia, que sepan encontrar la información que desean mediante los catálogos, que conozcan las normas de la biblioteca y las cumplan, y que sean conscientes de los servicios que, como usuarios, tienen derecho a recibir.

2. Ayudar a los niños y jóvenes a convertirse en unos buenos lectores que sepan elegir libros atractivos o que les interesen $-\mathrm{y}$ que esto les lleve a desear otros-, que descubran el gusto de leer en libertad —es decir, escoger qué, cómo y de qué manera- y que lo puedan llevar a cabo en nuestra biblioteca.

3. Ayudar a los niños y jóvenes, como personas que forman parte de una sociedad, a adquirir unos hábitos de comportamiento específicos que los enriquezcan y les ayuden a integrarse en la comunidad y en el país donde viven.

Llevamos casi treinta años cumpliéndolos con mucha profesionalidad, pero sin olvidar los ingredientes humanos: amor, voluntad, ilusión y alegría.

El Manifiesto de la UNESCO (1994) define la biblioteca como una fuerza viva al servicio de la cultura y de la información y un medio para conseguir la paz y la comprensión internacional.

¿Cómo conseguir ser esta fuerza viva permanentemente ? Descubrimos que podíamos conseguirlo a través de la lectura y decidimos apostar decididamente por ella.

La lectura es para nosotros esa oportunidad de descubrirnos a nosotros mismos a través de los ojos de los otros.

Es un camino que nos ayuda a reconocer lo que es realmente importante para nosotros y para los demás, es perderse en un no espacio no tiempo que nos da fuerza, luz, vida.

La lectura nos hermana a todos aquellos que hacemos las mismas lecturas ayudándonos a constituir una gran y coloreada familia: la de los lectores. Estos seres que nos perdemos en un espacio y un tiempo diferente al que nos rodea; y que sabemos encontrar en los libros soluciones y respuestas a muchas de les incógnitas que la vida lleva en ella misma; que somos cómplices de historias vividas, cada uno desde nuestro lugar y desde nuestro tiempo. 
Dice André Compte-Sponville (2001) que esa es la única razón para la que existan los libros, estar al servicio de la Vida:

Un libro puede cambiar una vida, y que quizás no valen más que por la vida que contienen, que suscitan o que pueden transformar.

Ese proceso de definir la lectura conlleva el reconocernos a nosotros mismos como lectores $y$, entonces, a través de ese reconocimiento, poder extrapolarlo y unirnos a todos los niños que quieren y pueden llegar a serlo.

Leer no tendría que ser un privilegio, sino un camino tan común que no tendría razón hacer cursos ni reuniones ni seminarios en los que intentar buscar formulas para hacer lectores. Leer es tan natural e innato como respirar, caminar...

Con los objetivos y nuestra pequeña verdad sobre la lectura empezamos a caminar y gracias a los niños y a ese acompañar se nos hizo evidente hace ya unos años ese camino, ese proceso silencioso que cada lector recorre hasta poder declararse con orgullo como tal: ¡Soy lector!

\section{4. ¿Qué es el proceso lector?}

A partir de los cuatro meses de vida en el vientre de la madre, los bebés recibimos las palabras como cajitas vacías, sin significado aún, de los adultos que nos rodean. Este hecho se convierte en el regalo más preciado y al mismo tiempo más asequible y barato de todos los que a lo largo de nuestra vida recibiremos. Palabras que como cajitas vacías a lo largo de la vida iremos llenando de significado.

Muy a menudo la primera que somos capaces de decir es papá y repetimos este 'papapapap' porque el adulto, a quien le corresponde este papel, sonríe. Lo repetimos sin saber que significa solo para hacerlo feliz, que para eso venimos los niños al mundo, para hacer felices a los adultos. Tanto es así, que hasta a veces nos dejamos maltratar para lograrlo.

Nuestra cajita correspondiente a la palabra papá, desde aquel momento, se ha ido llenando de significado y contenido, poco a poco, a veces gracias a las lecturas, y también por la propia experiencia y la relación de cada día con nuestro padre y algunos ya con nuestros hijos. Quizás sea por eso que a veces se nos hace difícil relacionarnos con ellos; quizás porque lo que contiene nuestra cajita es diferente a la de ellos y esperamos cosas que ellos no tienen en la suya y al revés.
¿Qué es ser padre? Pensamos que ya lo sabemos del todo cuando llegamos a serlo, pero seguramente cambia y se amplía cuando dolorosamente dejamos de serlo; o también, en este caso alegremente, cuando nos hacen abuelos. $Y$ así ocurre con todas las palabras que nos regalan, y que nos permitirán dar nombre a todo aquello que nos rodea, y que más adelante nos ayudarán a definir no tan sólo lo que veamos, soñemos o imaginemos, sin-o todavía más difícil- lo que sintamos.

Y ese dar nombre, ese definir, despertará el significado de cada palabra cada vez que las devolvamos al aire, al expresarlas con la voz o, silenciosamente, cuando las leamos reconvirtiendo ese texto que el escritor ha dejado humildemente en el papel y que cada lector convertirá en su texto, en su vivencia, en su experiencia; al poner a disposición de cada palabra escrita todo el significado que hasta entonces hayamos ido acumulando en cada cajita - caparazón mágico—, en cada palabra.

El proceso de dar significado a las palabras forma parte de la vida; $y$, por lo tanto, nace del misterio, de lo que no se puede explicar nunca del todo -como los cuentos, que nos permiten instalarnos en lo que parece imposible y vivirlo con la seguridad de un final feliz.

Ese proceso de vida que es la lectura comienza con la palabra, con la voz que dice, que comunica, que expresa, que empezó hace más de 92.000 años, cuando el homo sapiens descubrió el lenguaje -es decir, aprendió a modular los sonidos que emitía y sistematizarlos para decir ciertas cosas.

Pasaron 76.000 años más, hasta que los Cromañones empezaron a dibujar en sus cuevas con el fin de expresar lo que hacían, lo que veían, como vivían; y gracias a las imágenes que dejaron sobre las piedras nos hemos comunicado y hemos sabido muchas cosas de ellos.

Tuvieron que pasar muchísimos años más — de hecho solo hace 6.000 - hasta que la necesidad de expresar, de dejar constancia, de comunicarse llegó hasta el alfabeto, a la huella sonora de cada letra que forma la palabra.

La escritura es sólo la huella del lenguaje sobre las piedras, las tabletas de barro, los papiros, los pergaminos, la ropa, el papel, la pantalla del ordenador, el móvil... El soporte es diferente, cambia, evoluciona; las palabras no: son sólo huellas que hay que saber descifrar.

$Y$ esto tiene que ver muchísimo con la lectura y con el proceso lector. Pocas veces cuando leemos somos conscientes de que no podríamos 
hacer esta acción —la de leer-si otra persona antes no se hubiera expresado a través de la palabra escrita. Leer, por lo tanto, es un acto de comunicación, gracias a que lo que uno dice a través de unos signos, el otro -como los sabe descodificar- entiende, comprende, sabe.

\section{El proceso lector}

\subsection{La voz}

Empieza en la barriga de la madre cuando el bebé, a los cuatro meses, tiene completamente desarrollado ya el sentido del oído. Gracias, Sr. Tomatís, por descubrirlo y compartirlo

Voz que, después de nacer, será lo único que acompañará al bebé en el nuevo medio al que llega, una voz que le transmite seguridad en ese transito de descubrirse como un ser diferente y independiente de su madre; y es esa voz, acompañada de juegos y caricias, de música que da paso al sueño, la que le empezará a regalar esas cajas mágicas que son las palabras, aún vacías para él, pero que le harán estremecerse, emocionarse y le ayudaran a no sentirse solo.

\subsection{La imagen, lo que dice la voz}

Llegan las imágenes, huellas de lo vivido y visto por otros, que viven en los libros. Es el segundo paso de dar significado a las palabras. En él, los padres u otros adultos - con el libro y el bebé en la falda- continuarán con el proceso de dar nombre a lo que ven, relacionando las imágenes con su realidad más cercana, dando paso a descubrir que el mundo - la vida que nos rodea- está en los libros. La lectura para él bebé es durante este periodo de tiempo mirar y escuchar. Así comienza la construcción del propio imaginario, que le permitirá asociar la palabra a su imagen antes de aprender a leerla: El niño sabe, conoce lo que quiere decir, lo que significa, lo ve con los ojos de dentro.

\subsection{El alfabeto: la huella de la voz}

Esos adultos que cuentan y descifran las hileras de hormigas que son las letras, despiertan en los niños el interés por descubrir "lo que pone", contagiando sus emociones y el placer que sienten de ellos por saber leer. Leen esos pequeños cuentos que luego los niños se aprenden de memoria para hacer ver que ellos también leen.

Hasta que llega la escuela, donde se debería enseñar a leer para saber lo que otro ha escrito; leer para vivir, para conocer, para soñar, aportando lo que somos y el significado que guardamos en cada caja-palabra para recrear lo leído.

Durante este aprendizaje —que los niños pueden hacer por sí solos- se descubre que las palabras dejan huellas en los libros como las de los animales que se pasean por la selva, por los caminos... y que leer es sólo reconocer esos dibujos que el sonido deja en el papel para luego, al pronunciarlos, al leerlos, devolverlos de nuevo al aire, a la vida.

\subsection{Las palabras que narran: los libros}

En este siguiente paso, en el que ya leen por sí solos, hay que ofrecerles a esos lectores incipientes la posibilidad de encontrar buenos libros en la escuela, en la biblioteca de aula y en la general, en la biblioteca pública, en las librerías, en casa. Libros escritos a la luz de la inspiración, dibujados a su luz; editados sin esconderla en el proceso para permitir que su lectura o su escucha nos alimente y nos haga crecer como personas al ofrecernos la oportunidad de vivir otras vidas que no son las nuestras, a meternos en la piel de otros $y$, por tanto, a ensanchar nuestros sentimientos y vivencias.

Este proceso lector necesita de un ingrediente básico, portentoso y maravilloso en sus efectos, que es el amor, motor, puente, fuente de las relaciones y también de los conflictos. Ese tipo de amor, incondicional, que va hasta más allá de nuestra estancia en la tierra.

No se puede mientras lo guiemos y cuidemos ni imponer, castigar, controlar, obligar, exigir, comparar...

(En la tabla I, en la página siguiente, se detalla el proceso lector para cada una de las etapas evolutivas.)

\section{Los agentes lectores}

Observar este proceso de como - partiendo de la voz, se llega a la lectura- nos ha permitido descubrir a los diferentes agentes lectores y establecer sus responsabilidades individuales y colectivas en ese proceso de descodificar, interpretar, asimilar y alimentarse y crecer interiormente al realizarlo. Llevamos en ello 29 años, cuidándolo especialmente. $Y$ nos atrevemos a explicarlo porque las semillas han echado raíces, han florecido y estamos recogiendo sus frutos. 


\begin{tabular}{|c|c|c|}
\hline Edad & Autonomía en la biblioteca & Autonomía personal \\
\hline $0-3$ & $\begin{array}{l}\text { Haber descubierto que el libro es diferente a otros } \\
\text { objetos o juguetes que conoce. } \\
\text { Haberse descubierto a sí mismo y a su entorno más } \\
\text { cercano dentro de los libros con la ayuda del padre y } \\
\text { la madre. } \\
\text { Empezar a saber dónde están sus libros, cogerlos por } \\
\text { sí mismo intentando guardarlos en lugar. } \\
\text { Saber estar en la Hora del Cuento. } \\
\text { Haber aprendido a controlar el volumen de la voz. }\end{array}$ & $\begin{array}{l}\text { A partir de los } 8 \text { meses saber hacer la pinza con los dedos } \\
\text { para pasar las hojas de los libros (preferentemente de ropa, } \\
\text { plástico o de cartón). } \\
\text { Tener despierta la escucha atenta. } \\
\text { Haber comenzado a entender el "Ni tuyo ni mío sino de } \\
\text { todos". }\end{array}$ \\
\hline $3-6$ & $\begin{array}{l}\text { Saber dónde están los libros que desea, cogerlos por } \\
\text { él mismo y guardarlos en su lugar. } \\
\text { Saber poner su nombre en la entrada y colgar la } \\
\text { chaqueta y la mochila en su lugar. } \\
\text { Conocer y empezar a respetar las normas de la } \\
\text { biblioteca. } \\
\text { Poner los libros dañados en el Hospital de libros. } \\
\text { Empezar a contar cuentos. }\end{array}$ & $\begin{array}{l}\text { Practicar el "Ni tuyo ni mío sino de todos", respetar lo que es } \\
\text { de todos. } \\
\text { Aprender a descifrar lo que dicen las letras, las palabras, } \\
\text { reconocer los sonidos dibujados. } \\
\text { Ser un explorador de palabras. } \\
\text { Interpretar lo que dicen los libros, con ayuda de las imágenes } \\
\text { o solamente con las palabras. }\end{array}$ \\
\hline $6-9$ & $\begin{array}{l}\text { Respetar las normas. } \\
\text { Comenzar a desarrollar algún cargo en la biblioteca. } \\
\text { Responsabilizarse del libro que se lleva en préstamo, } \\
\text { no dañarlo y devolverlo cuando toca. } \\
\text { Ser capaz de contar cuentos. }\end{array}$ & $\begin{array}{l}\text { Conocer el alfabeto. } \\
\text { Leer sin ayuda de las imágenes. } \\
\text { Comprender lo que lee. } \\
\text { Ser capaz de buscar las palabras que no conoce por sí mismo } \\
\text { en un diccionario. }\end{array}$ \\
\hline $9-17$ & $\begin{array}{l}\text { Encontrar los libros que desean por ellos mismos } \\
\text { mediante los catálogos. } \\
\text { Desarrollar tareas concretas de la biblioteca. } \\
\text { Saber hacer búsquedas y utilizar la sección de } \\
\text { referencia de la biblioteca. } \\
\text { Comenzar a devolver a la biblioteca lo que se ha } \\
\text { recibido de ella a través del voluntariado o "jugando a } \\
\text { bibliotecas" }\end{array}$ & $\begin{array}{l}\text { Aprender a tener paciencia, a saber esperar y a tener respeto } \\
\text { y cuidado hacia los demás. } \\
\text { Haber comenzado a encontrar respuestas en los libros. }\end{array}$ \\
\hline $\begin{array}{l}18 \text { en } \\
\text { adelante }\end{array}$ & $\begin{array}{l}\text { Ser voluntario de la biblioteca después de recibir la } \\
\text { formación adecuada. }\end{array}$ & $\begin{array}{l}\text { Haber descubierto la lectura como una herramienta de } \\
\text { crecimiento personal. } \\
\text { Saber que en los libros se encuentran respuestas para la vida } \\
\text { de cada día. }\end{array}$ \\
\hline
\end{tabular}

Tabla I. Hábitos del proceso lector por edades

Nombraremos como agentes lectores a todos aquellos adultos - profesionales o no- que intervienen en el proceso lector.

\subsection{La familia}

Desde el principio nos dimos cuenta que si teníamos que agombolar a los niños hacia la lectura teníamos que contar con sus familias; y, no solamente porqué ellos no pueden por sí solos llegar hasta la biblioteca, sino porque ya teníamos claro que el proceso lector empieza en el entorno familiar: la voz es suya. La familia es por ello el primer agente lector.

La aparición de acciones orientadas hacia las familias no sucedió en el orden que ahora sabemos que tiene ese acompañar desde la voz a la lectura. En un principio, avanzamos a medida de las propias oportunidades, posibilidades y de los pequeños descubrimientos y las certezas que la experiencia de cada día nos proporcionaba.

Aún ahora -que todas las actividades y refuerzos están a la vez en acción cuidando espe- cialmente del proceso lector- sabemos que cada familia puede llegar hasta nosotros en cualquier fase de este agombolar la lectura; y nosotros hemos de saber indicarles y acompañarlos hasta el momento y actividad que sea más adecuada según sea su posición respecto de él.

La secuencia comenzaría, para los que no son usuarios de nuestra biblioteca o no han crecido en ella, al establecerse el primer contacto con las madres a través de la matrona y el pediatra en el Centro de Salud Público; o bien al recibir, al empadronarse en el ayuntamiento, nuestro tríptico que recoge algunos consejos e informaciones sobre las actividades y buenas practicas para las familias en nuestra biblioteca y sobre como establecer vínculos de calidad a través de los cuentos.

\subsection{La escuela}

Descubrir que una parte del proceso -la de descifrar la huella de la voz- le corresponde tradicionalmente a la escuela nos hizo tejer acciones hacia los maestros; y así apareció el tán- 
dem "escuela + familia + biblioteca" pedaleando juntos hacia la lectura para hacer posible y acompañar el paso de la oralidad a la literatura.

\section{7. ¿Que hacemos con ellos? Familia y escuela indistintamente siguiendo los pasos del proceso lector}

\subsection{Cuidar la voz}

- Taller de juegos de regazo y canciones de cuna: talleres para despertar la escucha atenta y abrir el paso a la lectura a través de la oralidad, de la mano de una profesora de música y una terapeuta.

- Lecturas en voz alta en la propia biblioteca, escuela, municipio: Aparecen en cualquier ocasión. Un profesional lee a los oyentes textos escogidos en voz alta.

- Horas del cuento: Las familias pueden, una vez despierta la escucha atenta de sus bebés, incorporarse a las Horas del Cuento que ofrecemos semanalmente desde que se inauguró la biblioteca. En ellas, junto a las familias con niños más mayores, las madres con los niños en el regazo escuchan juntos los cuentos que, de manera natural -como se contaban junto al fuego o ahora al lado de la cama-, transmiten emociones a la vez que regalan palabras y acunan o mecen a los pequeños con la voz y las imágenes de los libros. Es responsabilidad de los adultos que los tienen a su cuidado respetar sus ritmos y no forzar el tiempo que son capaces de escuchar. Pueden hasta dormirse sin que nadie se extrañe por ello.

\subsection{Cuidar la imagen}

- Cuando la lectura es mirar y escuchar: Desde el año 1983, nos saltamos la norma y empezamos a hacer carnés a los menores de 6 años que aún no sabían leer. Y, cuando en 1987 nos llegó la información de las Bebéthèques francesas, ya más seguros de lo que estábamos haciendo, empezamos a perseguir mamás embarazadas y establecer contacto con las escuelas cuna. Desde entonces ponemos en práctica la lectura "mirando y escuchando".

- La Bebeteca: El servicio de atención especial para la pequeña infancia (de 0 a 6 años) incluye -además de un espacio y un fondo de libros, elegidos según las necesidades de los más pequeños y las de sus padres-el préstamo de estos libros, charlas periódicas sobre su uso y el de los cuentos, y un asesoramiento y atención constantes. Tenemos establecida una colaboración permanente con el Servicio de Pediatría del CAP y con los cursos de post-parto que organiza la comadrona desde 1991.

- Exposiciones de libros bellamente ilustrados que no digan mentiras y den la cara. Cualquier excusa es buena para sacarlos del anonimato de las estanterías y mostrarlos.

\subsection{Cuidar la lectura}

- Plan de lectura en las escuelas (3) (Desde 1992): Presentación mensual en los centros de enseñanza de nuestro pueblo -en toda la primaria y hasta $2^{\circ}$ de ESO en el instituto- de libros y cuentos, del fondo duplicado de la biblioteca, que se dejan a disposición de los alumnos hasta la próxima presentación. Tiene dos áreas diferenciadas: la de cuentos y la de lecturas. Se practica la lectura en libertad: lee quien quiere, sin hacer trabajos posteriores, compartiendo en tertulias lo leído.

- Visitas de autores a la biblioteca y escuela: Invitamos a los lectores a conocer a escritores, a leer sus libros, a hacerles preguntas, a escuchar su pasión por escribir.

- Itinerarios literarios por el municipio: Recorridos por las calles de nuestra población dedicadas a escritores, haciendo paradas para escuchar alguno de sus textos.

- Espacio del lector: Tertulia literaria que se realiza en la biblioteca, dónde los lectores pueden compartir las vivencias, pensamientos y emociones que la lectura de los libros les proporcionan. No hay lecturas ni únicas ni obligadas.

- Conocer los amigos libros: Presentación de novedades, de libros especiales.

- Bosque de libros: En una casa de campo cercana hemos plantado árboles relacionados con los libros más importantes de la literatura universal y leídos en el Plan de Lectura, siguiendo la iniciativa del Pacto Andaluz por el Libro.

- Cuentos al aire libre: En nuestra población existe ya uno de los cuatro espacios de lectura (3) públicos diseñados especialmente para leer. El primero está situado en un parque cercano a la biblioteca. Los cuentos contados pueden aparecer allí o en cualquier ocasión que se lo merezca.

- Espacios familiares, de crecimiento, relación y reflexión para familias: 
Taula (4) Camilla: El niño lector está condicionado por la posición que sus padres tienen hacia los libros, los cuentos y la lectura; y, para acompañarlos, apareció este espacio familiar que da la oportunidad anualmente a doce familias, de niños que todavía no leen solos, de compartir sus dudas e inquietudes sobre cómo "utilizar" los cuentos como vínculos afectivos y como instrumentos de comunicación. Su desarrollo sigue la estructura de los espacios familiares dedicados al juego o a otros intereses compartidos respecto a la crianza de los hijos con ellos.

Crecemos leyendo: En espacio de adultos fomentamos con cuentos el desarrollo interior de los padres. Es un grupo de crecimiento y debate a través de los cuentos, de los libros y del diálogo que éstos puedan iniciar para tratar temas relacionados con la educación y la atención de nuestros niños.

- Espacios de crecimiento, relación y reflexión para profesionales (maestros de escuelas y guarderías):

Escuela de Verano: Se realiza en el espacio de formación junto con otros cursos certificados por el CIFE de la Universidad de Vic. Esta formación está dirigida conjuntamente a las familias, estudiantes y profesionales que se dedican a la pequeña infancia $(0$ a 6 años). Su contenido tiene la misión de acompañarnos armónicamente y equilibradamente a todos los que intervenimos en su educación.

Encuentros con los maestros: Iniciados ya antes de inaugurar la biblioteca, en ellos pretendemos, mediante la reflexión, establecer un intercambio profesional centrado en la educación mediante la lectura.

Con estos agentes de la lectura -familia y escuela- hemos caminado juntos haciendo trenza, no cadena, con el fin de que, si alguno de nosotros no cumple su responsabilidad en el proceso lector, y éste se rompe o se debilita su hilo, los otros lo puedan mantener.

Pero, ¿son suficientes estas acciones con los niños y jóvenes que tienen algún hilo de la trenza roto? Cuándo, por ejemplo, ni la familia ni la escuela les han regalado suficientes palabras como para tener un buen vocabulario y entender lo que leen.

¿Cómo atender a estos niños con dificultades especificas que no llegarían nunca a la lectura a pesar de estas acciones: niños en situación de riesgo, disminuidos sociales, psíquicos o físicos? Fue preciso entonces buscar un acerca- miento a los servicios sociales, una nueva declaración de intenciones, y buscar jóvenes que con voluntad quisieran dar y recibir al mismo tiempo y se comprometieran en nuevas y diferentes acciones:

- El Bibliomóvil: Jóvenes voluntarios, formados previamente, llevan semanalmente cuentos a casa de los usuarios que no pueden desplazarse a la biblioteca por dificultades momentáneas o permanentes o para reforzar a la familia en esta buena practica, y se los cuentan.

- El Padrinazgo: Jóvenes voluntarios, formados previamente, semanalmente dan atención individualizada a un usuario. Con su afecto, atención y cuentos, lo llevan hacia esta lectura libremente escogida y practicada, que lo ayudará a crecer interiormente y plenamente como persona. Conjuntamente, se realiza un libro de vida, en el que se dibuja el cuento que se ha mirado y escuchado, y se escribe en él, para luego ser leído.

Estos dos proyectos tienen cuatro tutores. Tres de ellos no pertenecen al personal de la biblioteca y colaboran como voluntarios también. Ellos son los que velan por su puesta en escena, forman a los voluntarios, atienden sus dudas y dirigen la manera de llevar a término la atención a los usuarios. Con ellos hemos empezado a abrir la biblioteca como espacio interprofesional hacia otros especialistas, en este caso, psicólogos y pedagogos.

- Equipo B: Acompañamos a diversos niños a realizar tareas propias de la biblioteca: registrar, hacer las fichas, forrar los libros nuevos, mientras hablamos de temáticas que les preocupan y que los libros reflejan, convirtiendo este espacio de tareas propias de la biblioteca en un espacio de relación y de comunicación y de desarrollo emocional y vivencial.

- No los podemos dejar solos: Niños y jóvenes en situación de riesgo llegan a la biblioteca, en horas pactadas con Servicios Sociales, para sentirse útiles y hacer tareas para recuperar la confianza en ellos mismos. Son siempre atendidos por un profesional de la biblioteca: no pueden dejarse solos.

- Taller de escritura: Nuestros amigos los libros nos invitan a la búsqueda de nosotros mismos, nos regalan mundos imaginarios y nos conectan con el mundo real. Este taller, de periodicidad semanal, conducido por la ilustradora Rosa María Curto, se dirige conjuntamente a niños de extrema sensibilidad y a otros en situación de riesgo social. 
- Plan de Lectura especial: Se ofrece mensualmente a los niños más "pequeños" de la Escuela de Educación especial Can Vila que no pueden desplazarse a la biblioteca y a los Jóvenes del centro de Justicia "Los Til.lers".

La base de todas estas actividades, ideadas para reparar hilos rotos, es principalmente el compartir cuentos. La voz abre de nuevo las puertas hacia las imágenes y el alfabeto, en edades superiores a las de los bebés y en situaciones diferentes. Hemos comprobado en muchos casos como, con un solo cuento, hemos podido restablecer relaciones, abrir nuevos caminos interiores de posición ante la vida y sobre todo hacia la lectura. Es un abrir ventanas y respirar a fondo; tanto, que llega hasta el alma.

Los cuentos son los cantos rodados que hacen de filtro del río de la vida. Nos ayudan a reír y a llorar, según nos sea necesario, estableciendo una sinergia con nuestros problemas no resueltos. Parten de lo que no se puede explicar, del misterio de la vida. Nos permiten continuar creyendo en todo aquello que no se ve ni se toca; lo que se ve con los ojos de dentro y se escucha con los oídos interiores. Se anclan en nuestro interior y sus semillas encuentran siempre un poco de tierra para germinar y crecer.

Durante este especial camino hubo un momento que se nos hizo evidente una nueva dificultad. Nuestro terreno no era el que solía ser. Nos habían cambiado la tierra, nos habían cambiado a los niños.

La mayoría de ellos han perdido su calidad de niño: no tienen libertad para ir solos por la calle, no tienen claros los límites, no son curiosos ni exploradores, evidencian falta de amor, no tienen despierta la escucha atenta, les cuesta expresarse, y, sobre todo, no saben por qué tienen que aprender a leer ni por qué, después, tienen que seguir leyendo. Son fruto de una sociedad, de una escuela que no educa, sólo domestica.

Decidimos entonces trabajar y evidenciar que nuestra biblioteca era un espacio educador.

\section{La biblioteca educadora}

La biblioteca educa no solo porque en ella los usuarios adquieren unos hábitos de relación y convivencia diferentes a los que se practican en otros lugares, sino porque se prioriza la lectura, propiciando encuentros educativos entre los niños y los libros, ofreciendo oportunidades que conduzcan a que los libros hagan de maestros (figura 1, en la página siguiente).
Educar es sacar a la luz, es decir, ayudar a ser conscientes de lo que ya se sabe; y eso es lo que hacen los libros. ¡Si se leen, claro!

\subsubsection{La lectura educa por ella misma}

Teníamos que demostrarlo y por eso nos atrevimos a diseñar un marco teórico (5).

\subsubsection{Marco teórico}

Para levantar el andamio de la biblioteca como un espacio educador y de convivencia, como un espacio de intervención socio educativa, partimos de la educación concebida tanto por la Carta de Ciudades Educadoras como por el Informe Delors, así como también por pedagogos como Francesco Tonucci y definida como la que:

1. Sobrepasa la escuela.

2. Comprende todas las tipologías educativas: formal, no formal, informal.

3. Comporta un proceso individual y colectivo.

4. Tiene una dimensión global.

La biblioteca se incorpora a la tarea de educar con la misma legitimidad que tienen los padres, los maestros, los vecinos, los ciudadanos o cualquier servicio de educación formal.

Algunas palabras de ciertos pedagogos pueden ayudarnos a reforzar esta legitimidad haciendo de eco al silencio profesional que a menudo acompaña a este posicionamiento:

- Peter Buckman: Educación no equivale a escolaridad.

- Paulo Freire: Aprendemos principalmente de nuestro entorno: amigos, grupos, personas con el mismo interés.

- Ivan Illich: La mayoría de personas aprenden cuando hacen lo que les gusta, son curiosas y quieren dar un significado a lo qué encuentran, son capaces de sostener una relación intima con los otros a no ser que hayan sido idiotizados por un trabajo inhumano o inhibidas por la escuela. Para crecer, una persona necesita en primer lugar tener acceso a las cosas, lugares y procesos, a los acontecimientos y a los documentos.

¿De qué manera una biblioteca cumple esta tarea, además de la función conservadora, la informativa y la social, que ya tiene asignadas, y la de acompañar el proceso lector de sus usuarios?

La biblioteca que quiere ser educadora tiene que ser una biblioteca inquieta, exploradora, 
que cree prioritariamente en la lectura como una herramienta de crecimiento personal. $Y$ eso ya lo éramos y lo somos. Se nos ofrecía por delante un largo camino de posicionamiento educador hacia los usuarios, los libros, y el hacer de puente entre unos y otros, partiendo del alma de la biblioteca, es decir, de la de los profesionales que la iluminan con las suyas.

\section{BIBLIOTECA EDUCADORA}

ESCUELA

\section{FAMILIA}

1er Objetivo

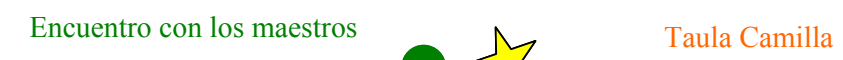

Visitas Didácticas Crecemos Leyendo en Familia

Plan de Lectura

Escuela de verano

Lecturas en voz alta

Sesiones formativas de

búsqueda de información

$2^{\circ}$ Objetivo

Bebeteca

Plan de Lectura Especial (Til·lers, Can Vila)

Biblioteca Arco Iris (Nicaragua)

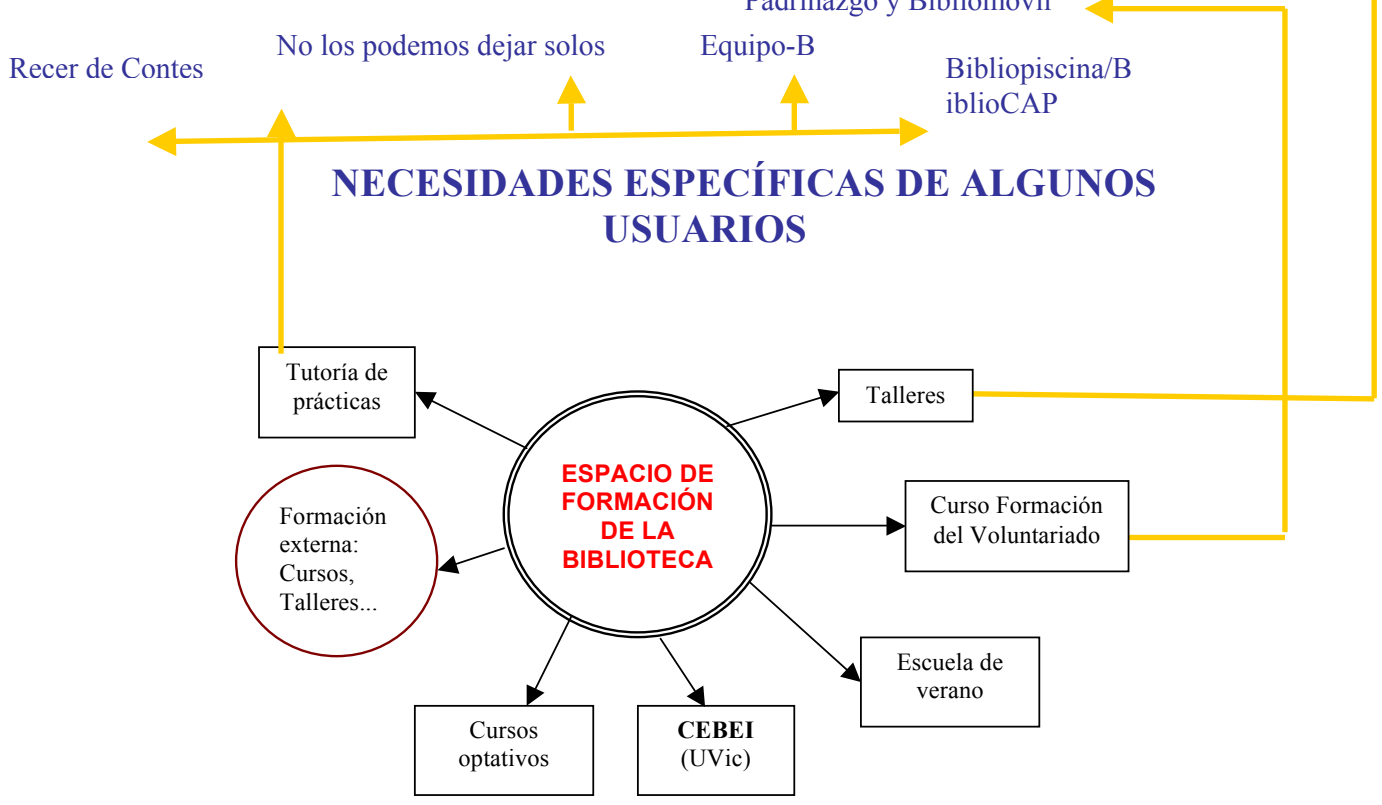

BIBLIOTECA

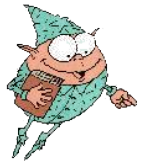

INFANTIL I JUVENIL CAN BUTJOSA

Un espacio de convivencia

Un espacio educador

Un espacio de intervención socio-educativa

Figura 1. La biblioteca educadora 
Llegar a ser educadora no sería nunca mediante "el hacer", sino "el ser". No lo somos sólo porque colaboremos con otros servicios públicos sociales, de salud, de aprendizaje, etc.-, Ilevando a cabo lo que podríamos denominar una gestión eficaz, sino porque lo queremos ser, y serlo depende de nuestra "filosofía" del centro, de esa esencia que ya teníamos arraigada.

Una biblioteca educadora es la que sabe que la lectura nos proporciona la oportunidad de vivir vidas que no nos pertenecen y, muchas veces, la complicidad de haber vivido la misma; una lectura que nos ayuda a cambiar, a evolucionar, a crecer, a adaptarnos a las vicisitudes que amablemente la vida nos regala, gracias quizás -entre otras virtudes que tiene- a que hemos sido capaces, mientras leemos, de ponernos en "la piel de los otros", de los que viven dentro los libros.

\section{La biblioteca es un espacio educador indiscutible}

Y si hablamos de espacio educador lo hacemos como dice Claudio Naranjo (2005) otorgándole, a éste, más que un espacio, la capacidad de ofrecer a todos los lectores - y principalmente a los niños- la oportunidad de adquirir conocimientos, de estructurar su inteligencia, de desarrollar facultades críticas, de desarrollar el conocimiento de él mismo y de los otros, de ser consciente de las propias cualidades y limitaciones, de aprender a vencer los impulsos indeseables y el comportamiento destructivo, de despertar permanentemente sus facultades creativas e imaginativas, de desarrollar un papel responsable en su vida en sociedad, de aprender a comunicarse, de ayudarlos a adaptarse y prepararse para los cambios, de tener una concepción global del mundo, de ser operativos y resolver problemas.

Misiones que en la biblioteca conseguiremos a través de la lectura íntima y silenciosa, cuando ya sabemos leer por nosotros mismos; y escuchada y compartida, mientras no sabemos.

Si partimos como ya hemos dicho de que, etimológicamente, educar es sacar a la luz; los libros de imaginación, su lectura, son los que iluminaran lo que vive en nosotros sin ser conscientes. No nos llenarán la cabeza de conocimientos, sino que nos harán participes del gozo de conocer, ayudándonos a tener visión y criterios propios, posicionándonos para que seamos capaces de tomar decisiones generadoras de vida.

La Biblioteca forma parte de la comunidad de aprendizaje porque, por ella misma, enseña, educa, da aprendizaje, es decir, herramientas para vivir y convivir. Una biblioteca educadora es pues la que promueve, respeta, agombola a sus usuarios con la lectura y les acostumbra, alecciona, civiliza, cría, cultiva, encamina, enseña, forma, instruye, nutre, orienta y pule, conjugando y practicado todos los sinónimos de la palabra educar mientras lo llevamos a cabo haciendo una evaluación permanente de nuestros objetivos educadores.

¿Quizás nuestra misión sea conseguir que cada ciudadano sea un agente de animación a la lectura, transmitiéndola como trasmitimos nuestra cultura, nuestras costumbres? Si llegáramos a este punto pienso que podríamos dejar de hacer acciones. Sencillamente, solo haría falta posibilitar el compartir sus beneficios.

Nos hace falta continuar trabajando desde las bibliotecas con coherencia, practicado de forma continuada con voluntad y con todo el corazón nuestra "filosofía de centro" con los atributos especiales (los siete sentidos ya comentados), trabajando con la fantasía como aliada en esta tenue línea que une la realidad con la imaginación, siendo un espacio de reflexión y de formación, educador y de convivencia, aprendiendo y creciendo cada día, gracias a los libros, gracias a la lectura.

\section{Bibliografía: libros que nos hacen de maestros (6)}

10.1. Para saber más de la lectura y acercar hacia ella a los que aún no la disfrutan

Comte-Sponville, André (2001). El amor a la soledad. Barcelona: Paidós.

Delahaie. Patricia (1998). Cómo habituar al niño a leer. Barcelona: Medici.

Equipo Peonza( 2004). Cien libros para un siglo. Madrid: Anaya.

Martin Garzo, Gustavo (2001). El Hilo azul. Madrid: Santillana.

Lewis, C.S. ( 2000). La experiencia de leer. Barcelona: Alba editorial.

Pennac, Daniel (1993). Como una novela. Barcelona: Anagrama.

Proust, Marcel (1989). Sobre la lectura. Valencia: Pre-textos.

Simona, Raffaele ( 2001). La tercera fase. Madrid: Santillana

10.2. Para descubrir leyendo que es la lectura (6)

- Birkegaard, Mikkel (2010). Libros de Lucca. Madrid: Punto de lectura.

- Funke, Cornelia (2005). Corazón de tinta. Madrid: Siruela (Las tres edades).

- Schami, Rafik (1996). Viaje entre la noche y la mañana. Madrid: Siruela.

- Schami, Rafik (1990). Narradores de la noche. Madrid: Siruela (Las Tres Edades). 
- Shaffer, Mary Ann; Barrows, Annie (2010). La sociedad literaria y el pastel de patata de Guernsey. Barcelona: RBA.

10.3. El poder de las palabras, oídas, escritas (6)

Emoto, Masaru (2003). Mensajes del agua. Barcelona: La liebre de marzo.

- Prestifilippo, Pablo(1998). Palabras mágicas. La Galera.

10.4. Sobre educación fuera de la escuela

Íllich, Ivan; et al. (1975). Educación sin escuelas. Barcelona: Península (Libro de bolsillo).

Morin, Edgar (2001). Los 7 conocimientos necesarios para la educación del futuro. Barcelona: Paidós.

Naranjo, Claudio (2005). Cambiar la educación para cambiar el futuro. Vitoria-Gasteiz: Eds. La Llave.

10.5. Trabajar con la fantasía como aliada

Rodari, Giani (1985). Gramática de la fantasía. Barcelona: El Hogar del Libro.

10.6. Trabajar des del alma, cuidando

Boff, Leonardo (2002). El cuidado esencial. Madrid: Trota.

Moore, Thomas (1997) El cuidado del alma. Barcelona: Urano.

Steiner, Rudolf (1978). ¿Como se adquiere el conocimiento de los mundos superiores?. Buenos Aires: Dédalo.

10.7. Conocer mejor a quién dirigimos nuestro trabajo

Haes, Udo de (1991). El niño y los cuentos. Madrid: Rudolf Steiner .

Hazard, Paul (1988). Los libros, los niños y los hombres. Barcelona: Juventud.

Paley, Vivian Gussin (2006). La niña del lápiz marrón. Argentina: Amorrrortu.

Postman, Neil (1988). La desaparición de la niñez. Barcelona: Circulo de Lectores.

10.8. Los cuentos, que son como actúan..

Carroll, David (1992). La transmisión de lecciones espirituales a través de los cuentos: La vida interior del niño. Barcelona: Robin Book.

Jean, Georges (1988). El poder de los cuentos. Barcelona. Pirene.

10.9. Para llegar a descubrir la fuerza de la palabra,

la lectura y los cuentos a través de la oralidad (6)

- Barber, Antonia; il; Le Cain, Errol (1987). La hija del mago. Barcelona: Lumen.

- Baronian, Jean Baptiste (1998). Con todo mi corazón. Barcelona: Beasco.

- Bogart, Jo Ellen; Fernández, Laura; Jacobson, Rick (1998). Tomas aprende a leer. Barcelona: Editorial Juventud.

- Cooney, Barbara ( 2004). La señorita Emilia. Caracas: Ekaré.

- Escala, Jaume; il: Carme Solé (1991). Los niños del mar. Madrid: Siruela.

- Escardó i Bas, Mercè (1992). Los ojos de Marina. Barcelona: La Galera.

- Haseley Denis; LaMarche, Jim (2004). El oso que amaba los libros. Barcelona: Juventud.
- Gliori, Debi (2000). Siempre te querré. Barcelona: Timun Mas.

- Jiménez, Àngeles (1996). El abrigo. León: Everest.

- Koopmans, Loek (2003). ¿Queda sitio para mi?. BarceIona: Eds ING.

- Lenain, Thierry. Habría que... Barcelona: Kókimos.

- Lionni, Leo (1997). Frederick. Barcelona: Lumen.

- Lujan, Jorge (2005). Mi cuerpo y yo. Barcelona: Kókinos.

- Manushkin, Fran; Himler, Ronald (2002) ¡Sal Bebe!. Barcelona: Rquer

- Nostlinger, Christine (1978). Pepito. Madrid: Interduc /Schroedel.

- Rodari, Gianni (2007). EL señor muerte dentro de una avellana. Barcelona: Blume.

- Sheldon, Dyan; Blythe, Gary (1996). El canto de las ballenas. Madrid. Kókinos.

- Waldorf, escuelas; Cámara, Sergi; Vázquez, Ivan (2002) La pequeña semilla. Barcelona: ING edicions.

- Williams, Margery (2005). El conejo de terciopelo. León: Everest.

- Wolfe, Frances (2001). Donde yo vivo, Barcelona: Juventud.

10.10. Las bibliotecas, espacios

con intencionalidad socio-educativa

Escardó I Bas, Mercè (2003). La biblioteca, un espacio de convivencia. Madrid: Anaya.

Petit, Michèle (2002). Del espacio íntimo al espacio público. Mejico: Fondo de Cultura Económica (Espacios para la lectura).

Petit, Michèle (1999). Nuevos acercamientos a los jóvenes y la cultura. Méjico: Fondo de Cultura Económica.

Wild, Rebeca (2002). Educar para ser: vivencias de una escuela activa. Barcelona: Herder.

\section{Notas}

(1) "Agombolar" según el diccionario catalán significa tener cuidado especialmente de algo, de alguien, definido por Leonardo Boff como el cuidado esencial.

(2) Para más información consultar la Web: http://bibut. parets.org.

(3) Recibió el Primer Premio de la Federación de Gremios de Editores de España el 2004. Desde el ayuntamiento, en 2008, se proclamó Parets como Pueblo Lector. Desde entonces, se hace evidente a través de actividades en estos espacios públicos y en todos los servicios y fiestas que estamos orgullosos de ser lectores.

(4) “Taula” en catalán significa mesa.

(5) Ese marco teórico se presentó en la UVic durante las Venes. Jornades d'Educació en Valors "Construint la ciutadania des de l'educació" y como obertura de las 1es Jornades de Biblioteques escolars de les Illes Balears, celebrades en Palma de Mallorca el octubre de 2009, Conselleria d'Educació i Cultura. Govern de les Illes Balears.

(6) Libros de imaginación, nuestros espejos internos. Se destacan con una viñeta en forma de cuadrado.

\section{Referencias}

[El autor ha preferido ofrecer las referencias de forma sistemática en el apartado anterior, para preservar el carácter también formativo del texto; y el equipo editorial 
ha estado de acuerdo en esta ocasión excepcional para facilitar el uso didáctico de este artículo; incluyendo en este apartado sólo las citas literales.]

Comte-Sponville, André (2001). El amor a la soledad. Barcelona: Paidós.

Naranjo, Claudio (2005) Cambiar la educación para cambiar el futuro. Vitoria-Gasteiz: Eds La Llave.
UNESCO (1994). Manifiesto de la UNESCO en favor de las Bibliotecas Públicas. París: UNESCO. http://www.unes co.org/webworld/libraries/manifestos/libraman_es.html.

Enviado: 2012-09-12. Versión corregida: 2012-09-19. Aceptado: 2012-09-20. 